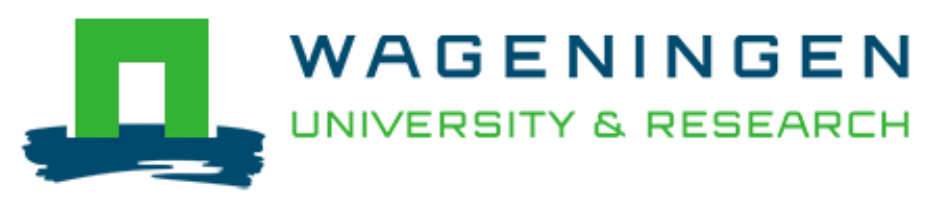

\author{
How to Cope with Working in an Open-space Lab? \\ Pautasso, M., \& van der Werf, W.
}

This is a "Post-Print" accepted manuscript, which has been published in "European Review"

This version is distributed under a non-commercial no derivatives Creative Commons (c) (1) (\$) $\Theta$

(CC-BY-NC-ND) user license, which permits use, distribution, and reproduction in any medium, provided the original work is properly cited and not used for commercial purposes. Further, the restriction applies that if you remix, transform, or build upon the material, you may not distribute the modified material.

Please cite this publication as follows:

Pautasso, M., \& van der Werf, W. (2017). How to Cope with Working in an Openspace Lab? European Review, 25(4), 679-687. DOI: 10.1017/S1062798717000266

You can download the published version at:

https://doi.org/10.1017/S1062798717000266 


\section{How to cope with working in an open-space lab?}

2

3

Marco Pautasso ${ }^{* \circ}$ and Wopke van der Werf ${ }^{* *}$

4

5

* Animal \& Plant Health Unit, European Food Safety Authority (EFSA), Parma, Italy, marpauta@gmail.com

** Centre for Crop Systems Analysis, Wageningen University, the Netherlands, wopke.vanderwerf@wur.nl

- The positions and opinions presented in this article are those of the authors alone and are not intended to represent the views or scientific works of EFSA.

Short title: working in an open space lab

\section{Abstract}

Open-space labs and research environments are increasingly common worldwide. They are supposed to facilitate interactions among researchers, but can be disruptive to those who need to be in a quiet environment in order to concentrate. This problem is increasingly felt across the natural, medical and social sciences, has a clear interdisciplinary and cross-cultural relevance, but has been the focus of limited attention. We propose some simple suggestions for researchers struggling in an open-space lab, based on a literature review and our experience in open spaces in various labs and countries (Australia, China, France, Italy, the Netherlands, Switzerland, the UK and USA) as undergrads, PhD students, postdocs, researchers and (W. van der Werf) professors. Our aim is to help researchers working in open-space offices and labs with some straightforward solutions that will make their life and work easier.

Keywords: communication, creativity, MOOC, open-plan office, perceived comfort, privacy, research, science, teleworking, training 
"We shape our buildings, and then our buildings shape ourselves" (Winston Churchill)

Open-space labs, whether dry or wet, are becoming more and more frequent worldwide. They are promoted because they are supposed to facilitate face-to-face interactions among researchers, ${ }^{1,2}$ but pose a big challenge to those who need to be in a quiet environment in order to focus and be productive..$^{3-7}$ Office designers are seeking to improve efficiency by means of open-space ${ }^{8-10}$ but might have actually ended up facilitating employee communication whether or not this supports the work to be done. ${ }^{11}$ The benefits of easier interactions brought by open-plan offices have indeed been found to be smaller than the drawbacks of increased noise and reduced privacy. ${ }^{12}$ In many open-space labs across the world there is thus the need for an agreed etiquette to solve this tragedy of the commons.

We propose ten simple rules for working in an open-space lab based on available research and reviews ${ }^{13-16}$ and drawing on our experience in open spaces in various labs and countries (Australia, China, France, Italy, the Netherlands, Switzerland, the UK and USA) as undergrads, PhD students, postdocs, researchers and (W. van der Werf) professors. These suggestions will need to be adapted to each particular open-space lab, depending on its mix of personalities, cultures and habits. The size of a lab is a key variable here: not all these rules are essential in an office with two-three colleagues, two of whom tend to be away for field work most of the time. But if you have to focus in a lab where on average other ten people are also there daily from before dawn to late night, then some kind of open space etiquette needs to be developed. Our aim is to help researchers working in open-space offices with some straightforward solutions that will make their life and work easier.

\section{Be quiet and inconspicuous, as if you were in a library}

In an open-space lab, whispering should be the rule, so as not to disturb the concentration of other people ${ }^{17}$. Research has shown that intelligible conversations between colleagues are the main source of noise annoyance in open-space offices. ${ }^{18-20}$ Avoid thus starting conversations from the other end of the lab, but move first close to the person you wish to reach. ${ }^{21}$ Also, there is no need to be loud when talking to someone who is close by (or is on the other end of the phone/skype connection). By speaking quietly, you will be more likely to be answered quietly. You can greet your colleagues just as effectively without shouting good morning or goodbye, by beaming with your eyes, smiling and/or waving. Moreover, one of the disturbances in open spaces is visual. If people around you are trying to concentrate, try to limit moving around exactly when a precarious timewindow of quietness has opened. Think before you move. Grab a mug of green tea at the same time 
as you check your snail mail pidgeon-hole and ask about your systematic literature search strategy at the library.

\section{Find a room for meetings, phone calls, parties and gossip}

Even if you are considerate, it is difficult to keep consistently a hushed voice during conversations; meeting and brainstorming rooms are there to be used. ${ }^{22,23}$ Research has shown that face-to-face conversation at a University does not increase by moving people from cell to open-space offices, but by providing formal (i.e. meeting rooms) and informal (e.g. collaboration events) opportunities for meetings. ${ }^{24,25}$ However, open-space offices can be particularly detrimental to concentration in the event of extrovert lab members using them to rehearse and perform in front of a mock audience. You might wish to remind these sociable research fellows that a lab is not a theatre stage. Lead by example: go to the bar, park or home for emotionally charged behaviour, recollections and conversations. A quiet open-space lab does not mean that researchers should not find the time to engage in social activities, getting to know each other and exchanging feedback on their research projects. It's just that these communication activities will be less disruptive if they tend to take place outside of the lab.

\section{Create quiet spaces for people needing them}

Quiet spaces should be available for those who need to concentrate, whether they are scholars intent in interpreting ancient manuscripts, software engineers trying to find a bug in their code or taxonomists looking for a good inspiration for how to name a newly discovered fungal species. A research institute with just open-space labs and with no individual rooms will result in people frequently distracted and interrupted, thus compromising creativity. ${ }^{26-28}$ Make agreements and develop rules about how shared quiet spaces are used to prevent that they are occupied preemptively. Everybody, but particularly a team leader, needs to have private conversations, which should sometimes remain confidential. ${ }^{29}$ Of course having a separate room does not mean that the team leader should not also spend much of her time in the lab, quietly interacting with individual researchers. But having a mentor and mentee all the time in the same room (although ideal from a learning perspective) is likely to lead to some stressful situations.

\section{Agree on accepted behaviour}

Discuss desired open-space behaviour with colleagues and agree on rules. One of the reasons for noise in open spaces is lack of clarity on desired behaviour. How many PhD students on the planet are or have been suffering because they have not managed to talk once and for all about open space manners with their lab-fellows? Express your personal needs and perceived (dis)comfort. ${ }^{30}$ Get the team leader and everybody else involved. Be creative: you might wish to devise a system of flags at 
every desk: a red flag implies that concentration is required and extra quietness is needed. Or you could set up an alarm system for excessive noise: ringing a designated bell (or banging a gong) makes it clear to everybody that silence is needed and people need to reset their voice volume to a quieter level (or go to somewhere else for their impromptu meeting). Be considerate also regarding thermal comfort: quietly ask for permission before opening or closing a window, or changing the setting of a thermostat. A whole day of keeping quiet and focusing can be counterproductive: everybody needs some breaks. ${ }^{31}$ But the problem in open-space labs is that it is often difficult to know in advance when people will happen to start a conversation about the planned holidays, the film they watched last night or the thunderstorm forecasted for the following weekend, so that it is impossible to plan in advance when to work on something that requires concentration and when instead to focus on tasks that can be tackled also under noisy conditions. Unless there is an agreement about e.g. set times for social interactions (e.g. 11 o'clock in the cafeteria, 4 pm in the common room), thus reserving the rest of the day for uninterrupted work.

\section{Adjust social mores}

Chat is the oil in our daily interactions, but never-ending or recurrent dialogue in an open space is impolite. Make loud people kindly aware that they are disturbing, they might not even have noticed. When doors and walls between rooms are not sound proof, loud conversations and phone calls can be disruptive also for colleagues in neighbouring areas. Remind colleagues at team meetings to e.g. please keep their mobile phones on mute, as if they were attending a chamber music concert. If chatting anywhere is the rule, place strategic signs requesting silence. A picture enhances the words. In some countries, people are now used to the concept of a quiet train coach - you could use this as a metaphor for how you wish your own lab to become. Adjusting social mores to enable focus work mode without unnecessary interruptions will improve motivation and the overall atmosphere in the lab. A poor workplace climate has instead been shown to correlate with various undesirable research behaviours. ${ }^{32}$ Of course, discussions on topics relevant to the research going on in the lab are important and should not be discontinued, just because one is afraid of disturbing other colleagues.

\section{Organize courses and summer schools in open-space lab etiquette}

Particularly in cultures and for personalities where whispering is not second nature, it is often difficult to achieve a long-term reduction of the stress caused by noisy interactions in open-space labs. Formal and informal training might be needed. What about developing a massive open online course on intercultural open-space etiquette? Has any staff development unit of a research institute already developed a course for PhD students, postdocs and faculty on how to reduce unwanted noise in open-space labs and corridors? At the very least, all research group leaders should find the 
time to give a short introduction about the expected open-space manners to newcomers, visitors and colleagues from other labs.

\section{Consider subdividing the lab in one for quiet people and one for loud ones}

Despite reminders and training to speak more quietly, some people tend to remain loud because of their outgoing personality and cultural background. ${ }^{33}$ The open office setting may thus not only be disturbing to people who need a quiet environment, but can also be constraining to people who function well in a more hustle-bustle environment (having to be consistently quiet so as not to disturb other people might make them feel despondent and unappreciated). However, people not fitting with the majority can be helpful in an open-space lab, e.g. if the rule is chatting, because having someone asking for silence will increase the productivity of everybody, but also if the rule is lack of vital communication, because having someone used to interacting will make it more likely for essential communication to happen. Nevertheless, splitting the team in two open-space rooms, one of which is reserved for those unable to concentrate if other people are loud, might be more rational than the traditional division of offices for PhD students and for postdocs, or for researchers working in different fields. If subdividing labs in those for quiet and those for loud researchers implies that researchers from different departments and disciplines need to be in the same office, then this would bring the additional benefit of removing some cross-disciplinary barriers, thus favouring interdisciplinarity. ${ }^{34}$

\section{Get used to open space}

Younger people seem to be less bothered by the setting of an open space..$^{35}$ Perhaps, if you get over the novelty of not having private space to yourself, you will be better able to work productively even in a chatty environment. You could treat it as an experiment, collect data about your productivity (and the one of your colleagues) in quiet vs. noisy labs and be surprised to find out that there are no significant differences, other things being equal? Sometimes, procrastination and distractions due to social media (rather than noisy colleagues) are the main factors causing lack of productivity. But if you do find that you tend to achieve more in a silent office, then it can be argued that it is your loud colleagues who actually need to get used to open space, by learning to be considerate when in the office.

\section{Wear a head set to exclude noise}

Most people benefit from a headset with music to concentrate better, although this noise masking effect can differ for different types of music. ${ }^{36}$ Of course if your headset music has to be so loud that it annoys other people in the lab, then you need to go back to rule number one. If you cannot concentrate with music on, you need a quieter place. Talk to your team leader. ${ }^{37}$ Ask human 
resources to decrease the speech transmission index ${ }^{38-41}$ of your lab (e.g. by adding carpets on the floor, cork panels on the walls, and plants wherever there is an empty corner). If nothing improves, consider moving to a research lab where these ten simple rules have been implemented.

10. Encourage teleworking

If everything else fails, it can help if researchers (whether loud or not) are allowed to work from home for those tasks that require concentration and can be done elsewhere. Sick absence leave rates have been shown to be higher in open-space compared to individual offices, thus showing the need for privacy and quietness created by large offices. ${ }^{42-44}$ Teleworking makes sense from an environmental perspective too. It should be encouraged for tasks such as reading, reviewing, writing papers, preparing talks/lectures, thinking, answering emails, making phone/skype calls, searching the literature, marking student essays, developing new courses, recalling ideas, crafting research proposals, and discussing. Even mentoring can sometimes take place successfully outside of the lab, e.g. at conferences, travelling to conferences, carpooling from the lab or when walking in the park. If all these activities were performed outside of the lab, then the lab might actually become the place to meet, thus making all these considerations redundant?

For the moment, health and well-being have been repeatedly found to be higher in individual offices than in open-plan ones. ${ }^{45-49}$ Health is in turn a key pre-condition for a productive environment. Working in a quiet environment is not a sufficient condition for writing a masterpiece, and it can be argued that noisy places have sometimes led to serendipitous insights that might not have been achievable by just reflecting whilst strolling in the countryside far away from an airport. However, not everybody is blessed with the ability to be inspired by loud small-talk and cacophonous settings. Eureka-like moments need to be nurtured and developed. Research often involves the performance of tedious tasks requiring the utmost concentration (or creative thinking about how to achieve the same result just as effectively but automating such tedious tasks). A quiet environment will make it possible for many researchers to achieve results of better quality by working shorter hours, a winwin situation for everybody involved, including the families of researchers. We wish all researchers in open-space offices good luck in finding the solutions that work for them to improve the comfort and performance of their working environment. We can influence how our buildings shape ourselves.

\section{Acknowledgements}

Many thanks to O. Holdenrieder, V. Queloz and R. Russo for helpful comments on a previous draft.

\section{References and Notes}



1. S. Andereggen, F. A. Zoller and R. Boutellier (2013) Sharing research equipment to bridge intraorganizational boundaries: the cases of Novartis and ETH Zurich. Research-Technology Management, 56, 49-57. doi:10.5437/08956308X5601082

2. H. A. Ricciotti, W. Armstrong, G. Yaari, S. Campion, M. Pollard and T. H. Golen (2014) Lessons from Google and Apple: creating an open workplace in an academic medical department to foster innovation and collaboration. Academic Medicine, 89, 1235-1238. doi:10.1097/ACM.0000000000000364

3. S. Banbury and D. C. Berry (1998) Disruption of office-related tasks by speech and office noise. British Journal of Psychology, 89, 499-517. doi:10.1111/j.2044-8295.1998.tb02699.x

\section{T. L. Smith-Jackson and K. W. Klein (2009) Open-plan offices: task performance and mental} workload. Journal of Environmental Psychology, 29, 279-289. doi:10.1016/j.jenvp.2008.09.002

\section{A. Haapakangas, V. Hongisto, J. Hyönä, J. Kokko and J. Keränen (2014) Effects of unattended} speech on performance and subjective distraction: the role of acoustic design in open-plan offices. Applied Acoustics, 86, 1-16. doi:10.1016/j.apacoust.2014.04.018

6. B. Purdey and D. Leifer (2012) A preliminary study of cognitive failures in open plan offices. Facilities, 30, 11/12, 472-487. doi:10.1108/02632771211252315

\section{A. Seddigh, E. Berntson, C. B. Danielson and H. Westerlund (2014) Concentration requirements} modify the effect of office type on indicators of health and performance. Journal of Environmental Psychology, 38, 167-174. doi:10.1016/j.jenvp.2014.01.009

8. U. Toker and D. O. Gray (2008) Innovation spaces: workspace planning and innovation in US university research centers. Research Policy, 37, 309-329. doi:10.1016/j.respol.2007.09.006

9. F. A. Zoller and R. Boutellier (2013) Design principles for innovative workspaces to increase efficiency in pharmaceutical R\&D: lessons learned from the Novartis campus. Drug Discovery Today, 18, 318-322. doi:10.1016/j.drudis.2012.12.012

10. J. Myerson (2014) Workplace and wellbeing. Wellbeing, 2, 1-18. doi:10.1002/9781118539415.wbwell068

11. S. Augustin (2014) Designing for collaboration and collaborating for design. Journal of Interior Design, 39, ix-xviii. doi:10.1111/joid.12020 
12. J. Kim and R. de Dear (2013) Workspace satisfaction: the privacy-communication trade-off in open-plan offices. Journal of Environmental Psychology, 36, 18-26. doi:10.1016/j.jenvp.2013.06.007 13. E. De Croon, J. Sluiter, P. P. Kuijer and M. Frings-Dresen (2005) The effect of office concepts on worker health and performance: a systematic review of the literature. Ergonomics, 48, 119-134. doi:10.1080/00140130512331319409

14. J. C. Vischer (2008) Towards an environmental psychology of workspace: how people are affected by environments for work. Architectural Science Review, 51, 97-108. doi:10.3763/asre.2008.5114

15. L. Windlinger (2014) Review zu den Einflüssen der Büroumgebung auf Arbeitsleistung. Working Paper des Instituts für Facility Management, Nr 1662-985X, Zürcher Hochschule für Angewandte Wissenschaften, Wädenswil, Switzerland.

16. V. Ruohomäki, M. Lahtinen and K. Reijula (2015) Salutogenic and user-centred approach for workplace design. Intelligent Buildings International, 7, 194-197. doi:10.1080/17508975.2015.1007911

17. D. Roche (2014) Top 10 rules of etiquette for an open office. Impact Office Pro Blog, 13 June 2014. Available online at: http://www.impactofficepro.com/blog-0/bid/183375/Top-10-Rules-ofEtiquette-for-An-Open-Office

18. A. Ebissou (2013) Gêne sonore en bureaux ouverts: Impact de la présence de plusieurs voix intelligibles. PhD Dissertation, INSA, Lyon, France. Available online at https://tel.archivesouvertes.fr/tel-01127491/

19. M. Pierrette, E. Parizet, P. Chevret and J. Chatillon (2015) Noise effect on comfort in open-space offices: development of an assessment questionnaire. Ergonomics, 58, 96-106. doi:10.1080/00140139.2014.961972

20. S. J. Schlittmeier and A. Liebl (2015) The effects of intelligible irrelevant background speech in offices-cognitive disturbance, annoyance, and solutions. Facilities, 33, 61-75. doi:10.1108/F-052013-0036

21. J. L. Swanson (2016) 12 etiquette tips for an open office work space. Communication diva blog, 23 March 2016. Available online at: http://www.communicationdiva.com/etiquette-open-officework-space/ 
22. R. Boutellier, F. Ullman, J. Schreiber and R. Naef (2008) Impact of office layout on communication in a science-driven business. $R \& D$ Management, 38, 372-391. doi:10.1111/j.14679310.2008.00524.x

23. E. V. Hoff and N. K. Öberg (2014) The role of the physical work environment for creative employees-a case study of digital artists. The International Journal of Human Resource Management, 26, 1889-1906. doi:10.1080/09585192.2014.971842

24. M. Lansdale, J. Parkin, S. Austin and T. Baguley (2011) Designing for interaction in research environments: a case study. Journal of Environmental Psychology, 31, 407-420. doi:10.1016/j.jenvp.2011.05.006

25. J. B. Stryker, M. D. Santoro and G. F. Farris (2012) Creating collaboration opportunity: designing the physical workplace to promote high-tech team communication. IEEE Transactions on Engineering Management, 59, 609-620. doi:10.1109/TEM.2011.2170995

26. T. Thanem, S. Varlander and S. Cummings (2011) Open space = open minds? The ambiguities of pro-creative office design. International Journal of Work Organisation and Emotion, 4, 78-98. doi:10.1504/IJWOE.2011.041532

27. F. Mozaffar, S. B. Hosseini and M. Bisadi (2013) The impact of office spatial aspects on creativity and innovation of architecture and urban design researchers. Architectural Engineering \& Urban Planning, 1, 34-40.

28. L. Thompson (2013) Give workers the power to choose: cave or commons. Harvard Business Review Blog Network, 27 March 2013. Available online at: https://hbr.org/2013/03/give-workersthe-power-to-choose-cave/

29. D. Gottsman (2014) Open office space etiquette: do's and don'ts. The Huffington Post, Blog, 10 Apr 2014. Available online at: http://www.huffingtonpost.com/diane-gottsman/open-office-spaceetiquet_b_5086027.html

30. P. M. Bluyssen, M. Aries and P. van Dommelen (2011) Comfort of workers in office buildings: The European HOPE project. Building and Environment, 46, 280-288. doi:10.1016/j.buildenv.2010.07.024

31. M. Savage (2017) The Swedes ditching desks to work from strangers homes. BBC, 6 Jan 2017. Available online at: http://www.bbc.com/capital/story/20161230-the-swedes-ditching-desks-towork-from-strangers-homes 
32. M. Baker (2015) Workplace climate: metrics for ethics. Nature, 520, 713. doi:10.1038/nj7549$713 a$

33. C. Brown, C. Efstratiou, I. Leontiadis, D. Quercia and C. Mascolo (2014) Tracking serendipitous interactions: how individual cultures shape the office. Proceedings of the 17th ACM conference on computer supported cooperative work \& social computing, pp. 1072-1081. doi:10.1145/2531602.2531641

34. B. Knapp, R. Bardenet, M. O. Bernabeu, R. Bordas, M. Bruna, et al. (2015) Ten simple rules for a successful cross-disciplinary collaboration. PLoS Computational Biology, 11, e1004214. doi:10.1371/journal.pcbi.1004214

35. H. Rasila and P. Rothe (2012) A problem is a problem is a benefit? Generation Y perceptions of open-plan offices. Property Management, 30, 362-375. doi:10.1108/02637471211249506

36. S. J. Schlittmeier and J. Hellbrück (2009) Background music as noise abatement in open-plan offices: a laboratory study on performance effects and subjective preferences. Applied Cognitive Psychology, 23, 684-697. doi:10.1002/acp.1498

37. Niklas (2012) Top 10 rules of open office etiquette. Logison blog, 19 April 2012. Available online at: http://www.logison.com/blog-article_/17588/blog-entry-19263/top-10-rules-of-openofficeetiquette

38. A. Haapakangas, E. Kankkunen, V. Hongisto, P. Virjonen, D. Oliva and E. Keskinen (2011) Effects of five speech masking sounds on performance and acoustic satisfaction. Implications for open-plan offices. Acta Acustica united with Acustica, 97, 641-655. doi:10.3813/AAA.918444

39. M. K. van de Poll, R. Ljung, J. Odelius and P. Sörqvist (2014) Disruption of writing by background speech: the role of speech transmission index. Applied Acoustics, 81, 15-18. doi:10.1016/j.apacoust.2014.02.005

40. M. L. Eriksson and L. Pareto (2016) Sound bubbles for productive office work. In: Lundh Snis, U. (ed) Scandinavian Conference on Information Systems. Springer, Berlin, pp 29-42. doi:10.1007/9783-319-43597-8_3

41. A. Haapakangas, V. H. Mervi Eerola and T. Kuusisto (2017) Distraction distance and perceived disturbance by noise - an analysis of 21 open-plan offices. The Journal of the Acoustical Society of America, in press. doi:10.1121/1.4973690 
42. C. Bodin Danielsson and L. Bodin (2008) Office type in relation to health, well-being, and job satisfaction among employees. Environment and Behavior, 40, 636-668. doi:

43. J. H. Pejtersen, H. Feveile, K. B. Christensen and H. Burr (2011) Sickness absence associated with shared and open-plan offices-a national cross sectional questionnaire survey. Scandinavian Journal of Work, Environment \& Health, 37, 376-382. doi:10.5271/sjweh.3167

44. V. Hongisto, A. Haapakangas, J. Varjo, R. Helenius and H. Koskela (2016) Refurbishment of an open-plan office - environmental and job satisfaction. Journal of Environmental Psychology, 45, 176-191. doi:10.1016/j.jenvp.2015.12.004

45. J. Varjo, V. Hongisto, A. Haapakangas, H. Maula, H. Koskela and J. Hyönä (2015) Simultaneous effects of irrelevant speech, temperature and ventilation rate on performance and satisfaction in open-plan offices. Journal of Environmental Psychology, 44, 16-33. doi:10.1016/j.jenvp.2015.08.001

46. B. Herbig, A. Schneider and D. Nowak (2016) Does office space occupation matter? The role of environmental satisfaction in the physical and mental health of employees. Indoor Air, 26, 755-767. doi:10.1111/ina.12263

47. P. J. Lee, B. K. Lee, J. Y. Jeon, M. Zhang and J. Kang (2016) Impact of noise on self-rated job satisfaction and health in open-plan offices: a structural equation modelling approach. Ergonomics, 59, 222-234. doi:10.1080/00140139.2015.1066877

48. M. Nido, E. G. Medici and D. Boch (2016) Verschiedene Bürostrukturen und ihr Zusammenhang mit Wohlbefinden und Gesundheit. In: lafob (Hrsg) Unternehmensgestaltung im Spannungsfeld von Stabilität und Wandel, Bd. II (Zürich: vdf Hochschulverlag AG an der ETH Zürich), S. 377-396. spaces. Applied Ergonomics, 60, 103-115. doi:10.1016/j.apergo.2016.11.007

\section{About the authors}

Marco Pautasso is a researcher interested in forest health, network epidemiology and biodiversity conservation, with expertise in writing literature reviews and scientometrics. 
339 Wopke van der Werf is an agro-ecologist and modeller, with expertise in landscape ecology, agro-

340 ecosystem services, pathway models and environmental risk assessment. 